\title{
Ritual ambiental Vichama Raymi de Paramonga, abundancia en la agricultura del maíz, el tacú tacú alimentos y guacas, impulsor de la civilización andina en el arcaico tardío y no "comercio ni pesca"
}

\section{Environmental ritual Vichama Raymi de Paramonga, abundance in agriculture of corn, tacú tacú, food and guacas, promoter of the Andean civilization in the late archaic and not "trade or fishing."}

DOI: $10.46932 / \mathrm{sfjdv2n4-084}$

Received in: March 1st, 2021

Accepted in: May 30th, 2021

\section{Dr. Henry William Marcelo Castillo}

Ciencias Ambientales

Institución actual: Universidad Nacional José Faustino Sánchez Carrión

Domicilio completo: Av. San Martin 699-700 Huacho Perú.

Correo electrónico: hmarcelo@unjfsc.edu.pe

Mg. Jorge Persi Principe Ramirez

Maestria en Docencia Superior e Investigación Universitaria

Institución actual: Universidad Nacional José Faustino Sánchez Carrión Domicilio completo: Jr. Rufino

Torrico $\mathrm{N}^{\circ} 889$ Cercado de Lima.

Correo electrónico: jprincipe@unjfsc.edu.pe

Dra. Kathelin Alexandra Lozano Vasquez

Ciencias Ambientales

Institución actual: Universidad Nacional José Faustino Sánchez Carrión

Domicilio completo: Urb Alameda del Naranjal MZ.J2 Lt. 29 distrito Los Olivos.

Correo electrónico: Klozano@unjfsc.edu.pe

Dr. Melvin Degnis Marcelo Castillo

Ciencias Ambientales

Institución actual: Universidad Nacional de Piura.

Domicilio completo: Av. Huancavelica $\mathrm{N}^{\circ}$ Perú. (puede ser institucional o personal, como prefieras)

Correo electrónico: mmarcelo@ unp.edu.pe

\section{Mg. Pepe Francisco Olaya Maza}

Maestria en Derecho Constitucional

Institución actual: Universidad Nacional José Faustino Sánchez Carrión 2 Domicilio completo: Calle Jose Olaya $\mathrm{N}^{\circ} 246$, Manzanares 1era Etapa-Huacho (puede ser institucional o personal, como prefieras)

Correo electrónico: polaya21@ hotmail.com

\section{Mg. César Raul Verastegui Paredes}

Maestria en Docencia Superior e Investigación Universitaria

Institución actual: Universidad Nacional José Faustino Sánchez Carrión Domicilio completo: Av San

Martin 294 lot 11- Huaura

Correo electrónico: cverastegui@unjfsc.edu.pe 
"El Padre Luis Teruel compañero del Padre Josef de Arriaga, dice que el origen de los Indios de los llanos dicen ellos, que fue el de sus guacas, comidas..." ( La Calancha1638 Crónica Moralizadora Tomo III)

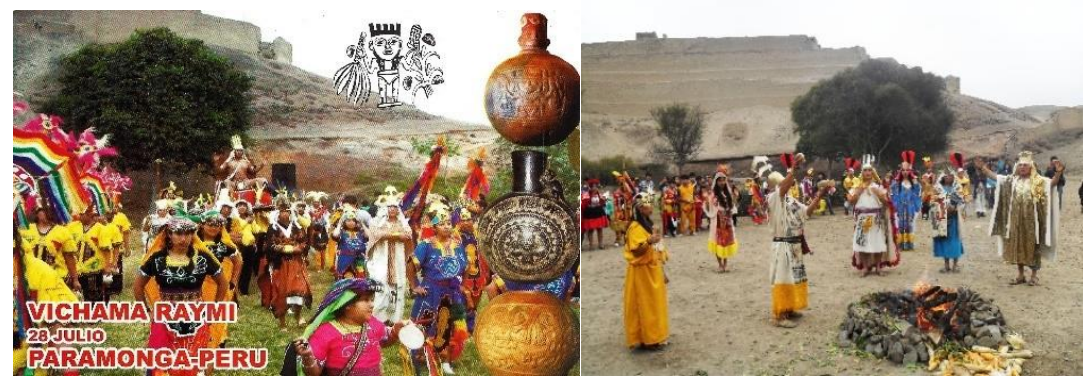

\title{
RESUMEN
}

Objetivo: Analizar el conocimiento en materia de investigación arqueológica en el Norte Chico del Perú con respecto al ritual religioso del Vichama Raymi de Paramonga. Métodos: Análisis de investigaciones publicadas en revistas científicas especializadas en la temática. Se centró el análisis y desarrollo, en el conocimiento en los últimos años, en materia de investigación arqueológica en el Norte Chico del Perú, cruce de información con datos antropológicos, ritos contemporáneos y fuentes de la cultura viva. Resultados: Descubrimiento definitivo sobre el cultivo y consumo masivo de maíz, camote, pepinos, guayabas y cientos de plantas domesticadas en el Arcaico Tardío de cinco mil años en Caballete y Huaricanga del Valle Fortaleza de Paramonga define que la sociedad de los inicios de la civilización andina fue agraria y no pesquera. Conclusiones: La forma del poder del Ritual ambientalista para el manejo social se expresó en las fiesta-festines de rituales del poder ambiental conocidos como los Vichama Raymis, las fiestas del origen de la abundancia de la agricultura, los alimentos y sanaciones de la Civilización Milenaria de Paramonga en donde el manejo de guerras psicosociales positivo a través del discurso de los sacerdotes o chamanes utilizó el tacú tacú o mistura de la pachamanca como dieta masiva-religiosa para estimular el intercambio la fuerza de trabajo colaborativo.

Palabras clave: Vichama Raymi, Mañaca, Aica, Guaca, ritual religioso, civilización, Paramonga.

\begin{abstract}
Objective: To analyze the knowledge in archaeological research in the Norte Chico of Peru with respect to the religious ritual of the Vichama Raymi de Paramonga. Methods: Analysis of research published in specialized scientific journals on the subject. The analysis and development focused on the knowledge in recent years, in the field of archaeological research in the Norte Chico of Peru, crossing of information with anthropological data, contemporary rites and sources of living culture. Results: Definitive discovery about the cultivation and mass consumption of corn, sweet potato, cucumbers, guavas and hundreds of domesticated plants in the Late Archaic of five thousand years in Caballete and Huaricanga del Valle Fortaleza de Paramonga defines that the society of the beginnings of civilization Andean was agrarian and not fishing. Conclusions: The form of the power of the environmentalist Ritual for social management was expressed in the festivals-festivals of rituals of environmental power known as the Vichama Raymis, the festivals of the origin of the abundance of agriculture, food and healings of the Millennial Civilization of Paramonga where the positive management of psychosocial wars through the discourse of the priests or shamans used the tacú tacú or mixture of the pachamanca as a mass-religious diet to stimulate the exchange of the collaborative workforce.
\end{abstract}

Keywords: Vichama Raymi, Mañaca, Aica, Guaca, religious ritual, civilization, Paramonga. 


\section{INTRODUCCION}

Mientras la arqueología en el Norte Chico del Perú se sume en una profunda crisis, en el contexto del 1er Congreso Internacional de Investigación Transdisciplinaria y 3er Congreso Universitario de Investigación (2015)" desde el cierre del Proyecto Bandurria en Huacho desde el 2011, la última celebración por sus 19 años de la puesta en valor de Caral, evento que se invitó a más de 45 periodistas nacionales y extranjeros para cubrir las actividades protocolares y avances de la investigación que han alcanzado el famoso centro arqueológico terminó en conflictos contra la libertad de prensa, de igual manera el Proyecto Arqueológico Norte Chico cerró por falta de presupuesto, el Proyecto Arqueológico los Huacos de Hualmay y Shicras de Huaral se recrudecen por falta de fondos económicos para la investigación. Sin embargo, el poder de los resultados científicos de serias investigaciones como el de la Universidad Cayetano Heredia, el Museo Field, el aporte de Mattew Piscitelli sobre el poder de los rituales en Huaricanga y el Museo de Arqueología de la Universidad Nacional José Faustino Sanchez Carrión (UNJFSC) en el valle fortaleza, abre una nueva etapa en la historia del Norte Chico del Perú.

Después de cuarenta años en los estudios de arqueología no se tenía claro acerca del consumo masivo del maíz en la civilización andina, ya Duccio Bonavia advertía "un problema muy serio lo plantea el sitio llamado Caral, en el valle medio de Supe, que desde los años cuarenta del siglo pasado conocemos como Chupacigarro, cuando fue descubierto por Paul Kosok (1965: 219,220-223). Es uno de los yacimientos sobre los que más se ha hablado en los últimos años y sobre el que se han tejido leyendas, pero sobre el que en realidad hasta este momento no se ha publicado ni un solo informe científico. En ocasión de una exposición que se hiciera sobre los hallazgos de Caral, se publicó en forma de libro una recopilación de los trabajos de Shady y su equipo, han escrito en diferentes revistas (Shady y Leyva, 2003). En dichos escritos el lector interesado se podrá darse cuenta de que no hay ningún sustento a las aseveraciones que allí se hacen; es más, se desconoce la literatura básica que se ha publicado sobre la materia (Pondré un solo ejemplo, en un trabajo que pretende tratar los orígenes de la civilización en "el área norcentral y el valle de Supe" se ignora el "Complejo Culebras" que creó Lanning y al que he referido, además ni siquiera se mencionan las investigaciones de Kosok, Willey, y Cobertt, Engel, Williams y Zechenter [Shady et al.,(2000) 2003: 51-91]). Incluso el libro publicado en el año 2004 es para el gran público, pero no tiene ningún valor científico (Shady, 2004)”.

El rol de la gastronomía peruana y su trascendencia a través de la historia en los orígenes de la civilización andina en Caballete, Huaricanga del Valle Fortaleza y el resto del Norte Chico nos remonta a las bases culinarias prehispánicas, con la intención de comprender mejor las preferencias de alimentos y su procesamiento alimentario. La falta de calor era sentida por los pobladores y por ello 
se hacían unos huecos en la tierra, para llenarlos principalmente con maíz, camotes y otros vegetales; de ésta manera calentaban a la Mamapacha uno de los elementos del universo que sufría por la falta de calor de la luz del Sol, podemos decir ahora con orgullo y certeza que la Pachamanca no solo es un plato común, este nace del afán de demostrar el cariño, la adhesión que tenía el indio con sus padres tutelares, el SOL, la TIERRA, LUZ-ABUNDANCIA, LA NOCHE, las Guacas, la HUANCA o piedra sagrada, base de la Pachamanca, es un plato que combina lo religioso con lo astronómico, por ende, entonces este plato nació en el ande Peruano y se masificó y se generó la abundancia agraria y alimentos-misturas en los festines-ferias conocidas en la actualidad como los Vichamas Raymis de Paramonga.

Al parecer el desarrollo de los rituales en el Valle Fortaleza en el preceramico estuvo marcado por rituales de poder de la elite como lo registrado en Huaricanga. La serie de estructuras ceremoniales en pequeña escala que se construyeron sirvió como lugar de pequeñas congregaciones, como la reunión de representantes de la comunidad o jefes de linaje que realizan ofrendas que quemaban en el piso, tal vez con el fin de ganarse el favor de las deidades o para resolver disputas legales. ( Matthew Piscitelli 2014)

En cuanto a las actividades reales que tuvieron lugar dentro de estas estructuras, los acontecimientos ocurrieron al encender fuego en la mayoría de todos los pisos. El análisis de polen y XRF confirman que ambas plantas domesticadas como el maíz (Zea mays), calabaza (Cucúrbita sp.), el camote (Ipomoea sp.), mate (Lageneria sp.), yuca (Manihot sp.), y frijoles (Pachyrhizus sp.), así como frutos silvestres como la guayaba (Psidium sp.) se colocan directamente sobre las superficies y quemados. Pequeñas diferencias en los colores de las marcas de quemaduras y enrojecimiento / ennegrecimiento de las herramientas de piedra sugieren los distintos tipos de materiales (por ejemplo, concha, hueso o piedra) pueden haber sido utilizados también. (Matthew Piscitelli. 2014)

Como podemos apreciar estos rituales de poder religioso basado en la abundancia de alimentos como una base de poder de Huaricanga, al parecer es emulado por la población a través de la pachamanca de basado en la dieta masiva del maíz. La PACHAMANCA se preparaba en el Valle Fortaleza como la comunión masiva del Ritual del Poder jugando así un papel determinante en el desarrollo civilizatorio del mundo andino, porque en ella está toda la cosmovisión andina. Mientras las elites se congregaban en pequeños recintos como representantes de las comunidades o jefes de linaje y realizaban ofrendas que quemaban en el piso (Mattew Piscitelli) para la comunicación directa con sus dioses, sinónimo de acumulación del poder político, rituales no públicos solo reservado en el acopio del saber y conocimiento, para el control e interpretación para el discurso psicosocial para las masas.

Otros, países podrán tener una preparación similar, con la misma técnica pero no encierran en sí “LA CONCEPCION DIALECTICA-AMBIENTALISTA DE DAR DE COMER AL UNIVERSO!”, 
porque este también presenta su debilidad en determinada época. Tal hecho lo evidencia los últimos descubrimientos de la Universidad Cayetano Heredia y el Museo Field de EEUU con el destacado trabajo de Jonathan Haas que demuestran que en el Arcaico Tardío en el Valle Fortaleza y el Norte Chico fue agrícola basado en el cultivo y consumo masivo de maíz. El Tacú Tacú (quechua significa mezcla o mistura) o la mistura de la pachamanca, debido a la llegada de las largas peregrinaciones temporales en la cual traían sus propios alimentos desde lugares lejanos de la Costa, Sierra y Selva tradición milenaria que hasta la actualidad se desarrolla se fusionaba y procesaba la mistura de aromas y sabores de los alimentos a la vez que también se procesaban los proto trueques (intercambio de productos agrarios y recursos energéticos) y con ello fusiones ideologías religiosas y dialectos que enriquecían el protoquechua. Mientras las élites se capacitaban en los rituales de pequeños recintos en la quema de los alimentos sagrados que le dotaban de poder del discurso comunicológico religioso ambientalista, rituales del poder para control social.

La cocina peruana procede de una de las culturas más antiguas del mundo, hace más 5,000 años en el Valle Fortaleza y el Norte Chico, el Dr. Jonathan Haas destacado científico del Proyecto Arqueológico del Norte Chico y del Museo Field de Chicago (EEUU) con la participación de Luis Huamán Mesía y Cindy Vergel Rodríguez, de la Universidad Peruana Cayetano Heredia, resolvieron muchas preguntas y discusiones que por más de cuarenta años se preguntaban sobre la presencia y la importancia económica del cultivo del maíz y consumo masivo en el periodo arcaico tardío (de3.000 a 1.800 años AC) en Perú "La evidencia directa para el consumo de maíz en el Arcaico Tardío proviene de coprolitos humanos (materia fecal conservado) se recuperaron de Caballete y Huaricanga (35). Los especímenes Coprolito fueron recuperados en contextos variables, incluyendo los residuos domésticos, relleno de construcción y habitación abandonada.

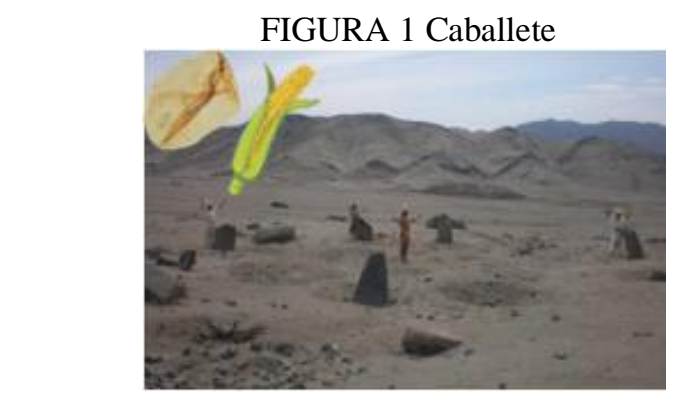

Nota Foto Patronato Patriceb de la Provincia de Barranca

Cuarentaiuno coprolitos fueron recuperados y analizados de Caballete y 21 fueron recuperados y analizados de Huaricanga el contextos del Arcaico Tardío. De ellos, 34 eran de humanos; 16 eran de perros domesticados, y los otros eran una mezcla de los cérvidos, zorro, y carnívoros no identificados y omnívoros salvajes no identificados. Entre los 62 coprolitos de todos los tipos, 43 (69\%) contenían granos 
de almidón de maíz, al igual que 23 (68\%) de 34 coprolitos humanos y 12 (75\%) de 16 coprolitos perros domesticados. El segundo grano de almidón más común en los seres humanos proviene de I. batatas (camote o batata), con sólo 9 (26\%) de 34 muestras, y 5 (31\%) de 16 coprolitos perro. El maíz constituye el almidón dominante en la dieta, como se refleja en los granos de almidón en los seres humanos y los perros. Los coprolitos también mostraron que la principal fuente de azúcar venía de guayaba y que las anchoas proporcionan proteínas. Las fechas de radiocarbono para estas muestras se muestran en los análisis. En Huaricanga tres fechas de radiocarbono del Arcaico Tardío y nueve fechas entre 2,370 y 3,240 a.C, Uno humano (CVR001) y un perro doméstico (CVR004) coprolito de esta operación proviene de una pequeño sector de basura que también produjo una fecha de radiocarbono de 2940 a.C. (AA-84576) tomado de fibras de plantas anuales. Ambos coprolitos contenían granos de almidón de maíz y el coprolito humano contenían fitolitos de maíz. Un coprolito de un omnívoro salvaje (CVR003), probablemente zorro, que contiene granos de almidón de maíz se asoció con una intrusión poco profunda en la superficie estéril.

Dos muestras de fibras de plantas anuales de la misma característica dieron edades de radiocarbono de 2,620 y $3,240 \quad$ a.C. AA-84570 y AA84581” (http://www.pnas.org/content/early/2013/02/19/1219425110), por lo tanto la sociedad fue agraria y no explícitamente pesquera ni tampoco fue el comercio, la pesca fue un complemento muy importante fuente inagotable de proteínas pero actuó como una forma de condimento saborizante de aromas para la alimentación, como hasta la actualidad se conserva esta tradición culinaria del comer con pedacitos de anchovetas secas con olluquito o el picante de charqui kan (papa, ají y achoveta salada y secada al sol) etc. hay varios peces, pero la anchoveta era la primera fuente de proteína, para la gente según el análisis de los Coprolitos, cada coprolito tiene menos de la mitad de una anchoveta, entonces es poco, la mayoría tenía anchoveta, pero tenía solo un poquito de anchoveta, entonces era parte de su dieta, pero solo era para obtener proteínas, es decir como un condimento saborizante quizás... (Jonathan Haas, 2013) estos importantes descubrimientos claves para la comprensión de la historia del Norte Chico fue publicado sus conclusiones en Proceedings of the Nacional Academy of Sciences.

FIGURA 2 Quilcas, Petroglifos de Caballete (mapa cosmogónico) y ritual huanca- meteorito escenificación deidad de Caballete


Nota: Foto Henry Marcelo C. 
Cabe señalar que estos importantísimos descubrimientos basado en el análisis micro botánicos y macro botánicos "simbólicamente abundantes" son complementados por los restos de concentración de arquitectura monumental o huacas expresión de la visión cosmogónica andina, los excedentes de la producción agraria lo utilizaron para construir el poder y prestigio para conseguir mayor cantidad de fuerza de trabajo y riquezas para la fiestas de intercambio de recursos naturales y energéticos=mitificación-ritual ambiental religiosa de los vichama raymis de parmonguilla, tal como se puede apreciar, "que algunas personas empezaron la agricultura dentro de los Valles aproximadamente entre los años 3000 a.C. $y$ se establecieron asentamientos dentro de los valles con sistemas de irrigación en las Chacras, para cultivo de varios recursos domesticados. Y estos sistemas crecieron y se desarrollaron en los próximos años, pero necesitaban proteína para eso necesitaban los recursos del mar y ¿cómo lo consiguieron?, yo pienso que tenían que atraer gente de otra parte de la costa y usaron ceremonias para atraerlos. Usaron la religión para atraerlos entonces, podían ofrecer a los pescadores una gran fiesta anualmente con "Gran fiesta de Pachamancas" anualmente, así como el Vichama Raymi, "Grandes fiestas de Intercambio" recursos agrícolas, por intercambio de recursos marítimos y para la construcción de sus Monumentos y participación en ceremonias religiosas, tenían que atraer gente para desarrollar su sitio para poder decir quizás que ¡mi sitio es el más grande!, jmi sitio es el mejor! Llegó gente de peregrinación de todo lugar...(Jonathan Haas, 2013)

De igual manera esto sucedió en todo el Norte Chico, como podemos apreciar en Caral en la que se realizaban una serie de actividades sociales, económicas y religiosas para afirmar el prestigio de la sociedad el poder de sus conductores la cohesión de sus integrantes y garantizar las relaciones dentro y fuera del estado. Se instalaban ferias en el centro de la ciudad realizando intercambios de productos dentro del contexto de celebraciones religiosas y asímismo se realizaban una serie de ceremonias donde la comida y bebidas eran distribuidas entre los participantes. Entre las ceremonias donde las comidas y bebidas que se realizaban estaba al pedir por todo lo obtenido. (Shady, 1999)

Sin embargo, estas tradiciones milenarias de los tacú tacús (misturas de pachamancas) o festines-rituales de poder o los llamados "Vichama Raymis" de Caballete y Huaricanga del Valle Fortaleza se basaban en el desarrollo de la agricultura hasta donde tenemos datos científicos publicados:...nosotros ahora ;sí!, tenemos la evidencia que fue la agricultura y no el comercio. Shady habla de algodón y peces y no es tan simple porque la evidencia de peces y conchas son de muy poco su consumo. Sin embargo tenemos evidencia de recursos agrícolas, en los sitios como Áspero, Bandurria, Bermejo (existían de plantas domesticadas en esos sitios) .pero esos sitios no tenían 
chacras, no tenían tierra arable para el cultivo, entonces el sistema era de "agricultura adentro" formalmente, muy desarrollado con muchas plantas y muchas cosechas, no era solamente una o dos; eran diez, doce plantas, muchas más... (Haas, 2013)

Los tacú tacú en quechua, "Mistura" del Huatio o la Pachamanca es una de las manifestaciones de fe masiva más antigua de nuestros ancestros que nace del afán de demostrar el culto ambientalista a la naturaleza como agradecimiento por las bondades que está brindaba a los antiguos pobladores del arcaico tardío del Valle Fortaleza. A lo largo de los años el ritual de la pachamanca ha perdido su significación desvirtuando su origen de ritual religioso filosófico de armonía ambientalista con la naturaleza expresado en los festines-rituales de la luz. La abundancia de la agricultura del poder o los llamados Aicas o Vichamas Raymis de Paramonga. Según Francisco Ávila, manifiesta un mito “...en el Tiempo de la gran oscuridad se quemaba chamizo y se ofrendaba constantemente al Sol tantos alimentos como chicha de jora, pero al no tener resultados satisfactorios. Huatio (sacerdote que ofrecía ceremonias) decide OFRENDARSE y se inmola lanzándose a uno de los huecos abiertos en la tierra. Entonces nace la PACHAMANCA”

Los orígenes de este plato-ritual se remontan al Perú precolombino; este cronista occidental en hablar del sacerdote Huatio en el año 1600 al recopilar los mitos existentes entre los pueblos de Huarochirí, en la sierra de Lima, señalaba la figura del dios Huatiacuri, más estrictamente watya quriq (recogedor de watya) hijo del poderoso Dios Pariaqaqa, de quien se decía que ocultaba su divinidad en una apariencia miserable y sólo se alimentaba de papas asadas en la tierra calentada llamadas "huatias o huatiyas", también tomó otros nombres como la Huatia o Guatia (del quechua "watya" o "watiya" o bien wetya) o Wathiya o Wajaña o Watia al parecer es el concepto del sacerdote diseñador del calendario agrícola de los antiguos peruanos, que estaba ligado a una profunda cosmovisión astral, asociaba también a los solsticios y equinoccios dividiendo el periodo de los sembríos en mitades y Huatiacuri aún se mantiene en la memoria colectiva de la comunidad campesina de Pararin es una población que convive con los pobladores del valle fortaleza, existen publicaciones de esta comunidad sobre el Dios Huatiacuri asociado a la danza en los festines de la luz y la abundancia agraria y el que come papas calientes, razón por la cual recibió ese nombre Huatia, y después llamada Pachamanca.

Este fragmento de este mito expresa en su esencia la articulación del génesis del pensamiento andino; OSCURIDAD $=$ NOCHE $=$ PACHACAMAC, SOL, LUZ, DIA = VICHAMA=AICA=ABUNDANCIA, HUECOS ABIERTO EN LA TIERRA = OLLA DE TIERRA = PACHAMANCA, quizás nunca lo sabremos cómo fue exactamente el mito psicosocial de los sacerdotes del Valle Fortaleza pero tenemos los registros de cartas annuas y crónicas españolas que nos narran el contexto de la poderosa comunicación oral expresado en el discurso chamanico del 
Vichama Raymi de Parmonguilla casi extinguida por la decidía de los alcaldes que gobiernan el distrito de Paramonga y que solo lo ven como un evento más...del montón.

La Pachamanca o el Huatio no es un pago a la tierra, es el sentido espiritual ambientalista de reciprocidad de amor, afecto y respeto por quien nos da la vida. No solo la tierra como elementos, sino a la naturaleza en si misma ya quienes lo complementan y coexisten con nosotros. Pacha $=$ universo y manca $=$ olla, por tanto LA PACHAMANCA es el "alimento del universo o alimento de la casa,", de la “Abundancia de la Agricultura la "Luz-Producción” o Vichama hijo del "Sol” o el Sol "Joven” es el periodo del solsticio de invierno de esos 22 días - años que veían crecer el sol hasta diciembre. Manjar para los dioses y una comunión con ellos. Hasta el siglo XVI simbólicamente se mantiene el ritual en el mito de los Vichama Raymis de Parmonguilla o Paramonga en la Carta Annua de Luis Teruel en 1617, la iglesia fue muy cuidadosa en ocultar los "Raymis" estratégicos de la Religión Andina siendo minimisadas solo como "FIESTAS" como se puede leer en el libro de Mario Polia Meconi en 1999 sobre la Cosmovisión Religiosa Andina en los documentos del Archivo Romano de la Compañía de Jesús 1581 -1752 en la cual se transcribe en el castellano antiguo las Cartas Annuas como las de Luis Teruel al visitar la Barranca y Cajatambo en 1617: Entre otros / se hallo en algunos pueblos destos vn nuebo rito para desechar las enfermedades. Hacían / cada año, a la entrada, o salida del Verano vna fiesta [ RAYMI]/ muy celebre a sus guacas la qual duraba, / tres, o quatro dias en vno dellos apostaban por certamen publico a quien mas corria hasta cierto termino señalado que a uezes solia ser de vna legua a una legua y media apartado del pueblo. Los q. I corrían yban del todo desnudos, y en el termino se hallaban el juez el qual con cierta tinta colo=/rada señalaba el pecho al que primero llegaba, y a los demas por su orden, y esta señal guardaban / ellos como ynsignia de su lijereza. (Teruel, 1617). Estas referencias de la gran actividad de las fiestas-festines rituales o (raymi-rituales) de la Barranca y del Norte Chico del Perú expresan en los registros de 1617 que aun conservaban una gran actividad de cultura física esa mezcla tradicional de los festines después de los deportes, junto al consumo de abundante chicha una forma de vino del maíz de alta calidad de contenido calorías y probióticos lo cual ayudaba a mejorar el estado físico de los atletas-chasquis de esos tiempos.

Seguían los gran chusma de pueblo y en medio yba vno con vn bulto de harnea [debe ser hanea = enea] o totora en figura de hombre que llamaban Aupi o puinac, que quiere decir lenfermedad, y este arrojaban en las primeras tierras que topaban del pueblo mas vezino con que / decían auian desterrado del suyo la enfermedad, y echadola a sus vezinos. Boluian después / muy contentos assi los de la apuesta como los demas, y hallaban en cierto paraje todo el resto / de la gente que les salía a receuir con tambores, y flautas, y auiendo el Curaca (que era el que ponía / el certamen) dado los premios a los que auian corrido, se juntaban en borrachera publica q. duraba / vno o dos dias. Y porque los curas no reparassen 
en tanta publicidad hacían estas fiestas [ RAYMIS] / en las del Corp. a titulo de celebrar las del SS.mo sacramento (Teruel, 1617).

Apenas avía parado cuando luego llego allí Pachacama (que es una guaca muy célebre y muy común en este reino, y está a cuatro leguas de Lima junto al mar a la parte del Sur); el cual despedazo el muchacho a vista de la madre y le dio los dientes como semilla de maíz, los huesos para semilla de yerbas y camotes y la carne para semilla de pepinos y otras frutas y desde entonces acá dicen no a ver ávido falta de estas cosas. (Teruel, 1617).

La tradición abundancia-luz de los llamados Ychsmas (par luz - noche) Vichamas Raymis de Paramonga es cobar un pozo en la tierra echar leña para producción de fuego y en ella echar el maíz, el camote y los pepinos y/o lúcumas invocando el "devolver a su hijo Vichama a la Pachamama" es el milenario pedido del regreso o el renacimiento de la luz para la producción de los campos (crecimiento del sol joven o Vichama hijo del sol, esta tradición, extrapolada al entierro a los niños muertos en las huacas de los gentiles como retribución simbólica de entregar el espíritu de Vichama, "si se hace con mala fe la huaca llama a su hijo menor de estas como retribución para el equilibrio de $s u f e$ ", y los creyentes tienen que ir a darle una ofrenda de igual manera, cobar un pozo en la huaca con leña y fuego en donde se deposita el maíz, camote y lúcumas o pepinos (también asociado que para sembrar la lúcuma lo tiene que hacer un perro sino la Pachamama se lo lleva) para calmar la ira de la maldición de la huaca, se realizaban peticiones a sus huacas o padres en determinadas épocas del año para merecer su ayuda y como tiene naturaleza su par (noche - luz) reflejado en la tradición de gobierno de los Huauques (hermanos) Ychsma-Ychma, Vichama-Pachacamac, surgió como un concepto dual (AICA, YCHSMA, CASTELLANIZADA COMO UNA SOLA PALABRA CONCEPTUAL EN LA BARRANCA ANTIGUA-VICHAMA) podían ser hermanos, esposos, siempre los más habiles etc. siempre la dualidad del gobierno de reciprocidad cuando sus huancas o apus se encuentran con dificultad, ellos los confiere su ayuda.

La falta de calor atribuida a la luz del sol era sentida por los pobladores y por ello se hacían unos huecos en la tierra para llenarlos principalmente con papas, camotes, y otros vegetales; de esta manera calentaban a la Pachamama para la armonía ambiental del cosmos expresada en la abundancia de la agricultura. Una versión más de la mitología sobre los alimentos, esta vez acerca del maíz. Corresponde al testigo Pedro Sarmiento, también sacerdote secundario del pueblo de San Pedo de Hacas, del ayllu de Yanaque, 64 años de edad, quien declara ante el visitador Noboa, el 28 de enero de 1657 lo siguiente: ... cuando cosen todas sus chacras y sementeras recogen las mazorcas que llaman airiguas y misasara y mamasara y de ellas hacen un ramillete en un palo de maguey con ramos de molle y lo llevan en la mano un indio mocetón en un sitio donde está el ídolo Tauris se juntan todos los del pueblo 
y las viejas con tamborcillos bailan todos el baile supersticioso de la airigua y hacen esta fiesta a sus malquis e ídolos porque le ha dado maíz y comidas y beben toda la noche hasta que se emborrachan y después de echa esta fiesta los dichos ministros de ídolos, parte de aquellas mazorcas del dicho ramillete las hacen chicha y parte de ellas con la dicha chicha ofrecen y queman en sacrificio...(Expediente $N^{o} X I$ del legajo 6 del Archivo Arzobispal de Lima). Fuente: Pacarina del Sur.

http://www.pacarinadelsur.com/home/indoamerica/81 -héroes-fundadores-y- origen-de-losalimentos-en-la-memoria-de-los-pueblos-andinos.

En el arcaico tardío en el Valle Fortaleza la evidencia física de las primigenias misturas de los alimentos de la costa, sierra y selva se dio al parecer por las condiciones ambientalistas de este Valle, y los Valles del Norte Chico para lo cual llegaban alimentos de los confines del mundo andino y se mezclaban sus aromas y sabores en los rituales de la Pachamanca; "se traía de todas partes de la costa, también de la Sierra y Selva porque tenemos polen de plantas de la Sierra y Selva; tenemos polen de varias partes del Perú profundo. En los sitios grandes como Caral, Caballete y Huaricanga hemos encontrado rastros de grandes campamentos temporales, en esas grandes pampas; donde no había construcciones, hay pedacitos de conchas, lajas de piedras, pozos con unas capas de piedras quemadas. Solo para protección del viento nada más; nosotros hemos escavado en esas grandes pampas y encontramos evidencias de esos campamentos, probablemente donde se cobijaban de las largas peregrinaciones. También en Caral se da ese desarrollo" (Haas, 2013)

No solo se desarrollaban los rituales sino ya se dedicaban a procesar sus alimentos como el maíz, frejoles, etc. a través de la técnica de la LLunka; que es el proceso mediante el cual el alimento se lava y se remoja durante dos horas y para luego ser sobado suavemente sobre un batán, con la finalidad de eliminar la cáscara, luego se procede a dejar secar al aire. Aplicado principalmente a cereales, este proceso se ha encontrado en el Valle Fortaleza "así como cuchillos, martillos, moledoras y encontramos evidencias de maíz en la mayoría de las herramientas; estaban procesando maíz, no solo existen chacras de maíz y mucho de maíz, sino que estaban procesando el maíz” (Haas, 2013)

"A comienzos del XVII el padre Diego Chávez Holguín, en su Diccionario Quechua, ya consideraba la denominación "Pachamanca". Este vocablo quechua proviene de la conjugación de dos raíces Quechuas: "pacha” que significa tierra y "manka” que significa olla, que literalmente vendría a ser olla de tierra". Lo que significa que el termino Pachamanca era una concepción conocida y que estaba referida al procedimiento de cocción de diversos tubérculos y otros productos agrícolas en un hoyo abierto en la tierra con terrones y/o piedras caldeadas". (Proyecto de ley $N^{\circ} 3446 / 2013-$ CR). Sus orígenes datan de unos 7.000 a 8.000 años antes de cristo aproximadamente, ya que se ha encontrado en un abrigo rocoso llamado "Telarmachay", ubicado en San Pedro de cajas, cuyas 
evidencias de piedras caldeadas con las que el hombre andino cocía sus alimentos de carne de camélidos y otros animales silvestres, lo cual demostraría la antigüedad de esta milenaria costumbre. (Proyecto de ley $N^{o} 3446 / 2013-C R$ )

FIGURAS 3 Pachamanca con ídolo Dios Vichama, distribución de Pachamanca en el Vichama Raymi de Paramonga y Dra. Winifred Creamer con lugareños en Caballete.
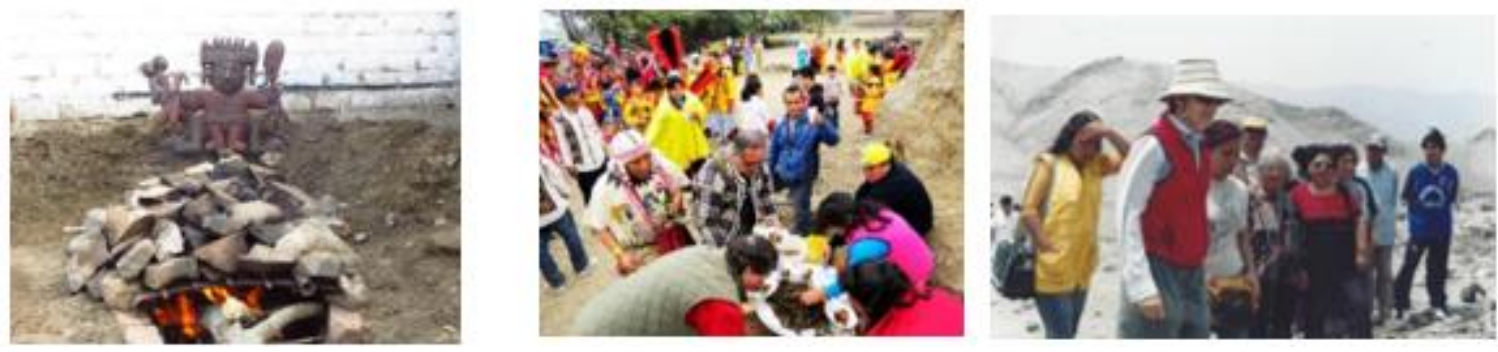

Nota: Foto Patronato Patriceb de la Provincia de Barranca.

Entonces estamos sosteniendo el descubrimiento del origen del consumo masivo del Tacú tacú o la misturas de la pachamanca en el arcaico tardío y no del consumo contemporáneo de la pachamanca y después de haber analizado el mito y su comprobación científica con los ORIGENES DEL CONSUMO MASIVO DE LA MISTURA DE LA PACHAMANCA EN EL ARCAICO TARDIO EN EL VALLE FORTALEZA, EN LOS (FESTINES-RITUALES DE PODER) O VICHAMAS RAYMIS MILENARIOS DE CINCO MIL AÑOS podemos decir ahora con certeza que la Pachamanca y su consumo masivo se desarrolló en el "Valle Fortaleza" porque se han encontrado físicamente demostrable restos de Pachamanca de consumo masivo "yo pienso que la pachamanca era la principal manera de preparar su comida todo era pura pachamanca, por todo lado... si, hemos encontrado muchas muestras de pachamanca en todos los sitios existen áreas muy, muy, grandes en Caballete, por ejemplo existen puros restos de pachamanca" (Haas, 2013)

Esta tradición de los festines o Vichamas Raymis del ritual de la Pachamanca milenaria del Valle Fortaleza y del Norte Chico en el solsticio de invierno fue el eje del ritual del poder inca "para la cosmovisión andina esta constelación en el mensajero cósmico era la estrella encargada de brindarle su vaso de chicha y su alimento que lo llevaba en su alforja al sol y además llevaba el alimento que se había cocido en los huecos donde se apagaban los restos de las chamizas. Entonces se da una sincronía: como es arriba es abajo. Por ende se cumplía el equilibrio y todo volvía a la normalidad en el tiempo previsto" (Proyecto de ley $N^{o} 3446 / 2013-C R$ )

La precisión del solsticio de invierno se pierde en el tiempo desde el 21, 27 de junio, (aquí en el Valle Fortaleza-Perú), la noche más larga y el día más corto, motivo para agradecer al universo para que le devuelva la luz para el Ritual del Poder del "Ychsmas" Aicas o Vichamas Raymis de Paramonga. Es el 27 de Junio y Julio del Ritual Milenario del Tacú Tacú o la Mistura de la Pachamanca, 
para recibir a la gran fiesta el 28 Julio el más poderoso RITUAL DEL PODER DEL VICHAMA RAYMI de PARMONGUILLA O PARAMONGA en este día nuestros ancestros conmemoraban el inicio del nuevo año andino como símbolo estratégico psicosocial comunicológico del mañaca (quechua antiguo fusión), crisol de todas las sangres de la civilización andina.

El Vichama Raymi de Parmonguilla el festín-ritual masivo del poder más antiguo del mundo andino fue el paradigma iniciático del Inti Raymi de Huánuco Pampa y del Cuzco. La Fiesta al Sol, era una fiesta donde se definía que el Sol estaba débil y por consiguiente la Tierra se enfermaba, se preparaban Huatias llamadas posteriormente la Pachamanca. Se han realizados trabajos de investigación científica destacables y se han escrito artículos científicos del Periodo prehispánico como los trabajos de Jonathan Haas, Ruth Shady Solís, Guillermo Cock y Elena Goycochea, Krzysztof Makowski, María Rostworowski, Rodolfo Tafur y Maritza Villavicencio; Virreinato con Rodolfo Tafur, Eduardo Dargent, Luis Repetto, Humberto Rodríguez; y República con Isabel Álvarez y Sara Beatriz Guardia. Además, están presentes en la Revista "Guara" del Museo de Arqueología de la UNJFSC, escritos populares de Paramonga y del norte chico, y en las actuales ceremonias chamánicas.

De igual manera destaca la herencia de la mañaca o crisol de la civilización andina cuando al Identificar, en el territorio peruano, los diversos modos de vida desarrollados por los diferentes grupos étnicos que han existido con anterioridad a la época Inca y española/europea, nos lleva a reconocer que esa diversidad ha generado diferentes formas y procesos de relacionamiento cultural (Ramírez Villacorta, 2021)

Existe una representación del mes de junio, (alimentando al dios sol) según Guamán Poma de Ayala las sociedades pre-incas e incas, dieron gran importancia al desarrollo agrícola basado en el maíz y tal es así que lo hemos visto simbolizado a través de mantos, huacos y grabados como las cerámicas del estilo Pativilca "la cópula divina de la sabiduría de Paramonga" que puntualizan las actividades de la relación de los festines del Vichama Raymi el trueque, el ritual chamanico, los dioses ancestrales, siembra, maduración de las plantas y cosecha, las guacas y huancas (piedras sagradas) asociados al comportamiento de la fauna existente, con el fin de programar sus tareas según los fenómenos climatológicos y atmosféricos observados en el entorno, asociándolo a los solsticios y equinoccios que dividían el año en mitades correspondientes y opuestas, por ejemplo los incas tenían en cuenta los siguientes festejos: - Capac Raimi Quilla, Luna de la Gran Fiesta del Sol, equivalente al mes de diciembre o descanso. - Zamay Quilla, Pequeña Luna Creciente, enero, mes del crecimiento del maíz. [Cita requerida] - Hatun Pucuy Quilla, Gran Luna Creciente, febrero, tiempo de vestir taparrabos. - Pacha Pucuy Quilla, Luna de la flor creciente, marzo, mes de maduración de la tierra. - Ayrihua Quilla, Luna de las espigas gemelas, abril, mes de cosecha y descanso. - Aymoray 
Quilla, Luna de la cosecha, mayo, el maíz se seca para ser almacenado. - Haucai Cusqui Quilla, junio, cosecha de papa y descanso, roturación del suelo. - Chacra Conaqui Quilla, Luna de riego, julio, mes de redistribución de tierras para la agricultura - Vichama Raymi de Paramonga, Universo, ritual del poder, julio, en agradecimiento para la fertilidad de las tierras símbolo del nacimiento de la civilización andina. - Chacra Yapuy Quilla, Luna de siembra, agosto, mes de sembrar las tierras. - Coia Raymi Quilla, Luna de la fiesta de la Luna, septiembre, mes de plantar. - Uma Raymi Quilla, Luna de la fiesta de la provincia de Oma, octubre, tiempo de espantar a los pájaros de los campos recién cultivados. - Ayamarca Raymi Quilla, Luna de la fiesta de la provincia de Ayamarca, noviembre, tiempo de regar los campos.

De toda esta explicación podemos deducir entonces que en el Arcaico Tardío en el Valle Fortaleza hace cinco mil años se consumía masivamente maíz y el ritual del Poder se asoció al Tacú tacú o mistura de las pachamancas producto a esa mezcla de insumos de alimentos traídos de las épicas peregrinaciones religiosas desde los lugares más remotos del mundo andino de la costa, sierra y selva desde tiempos inmemorables existió un padre (Dios) que se llamaba HUATIO el mismo Vichama. Apenas auia parido cuando luego llego allí el Pachacama (que es una guaca muy celebre, y muy común en este reino, y está a cuatro leguas de Lima junto a la mar a la parte del Sur); el cual despedazo el muchacho a vista de la madre y le dio los dientes para semilla de maíz, los huesos para semillas de yucas, y camotes, y la carne para semilla de Pepinos, y otras frutas, y desde entonces acá dicen no haber habido falta de estas cosas (Teruel, Barranca 1617) que este da nacimiento a un plato de nuestra gastronomía llamada actualmente la HUATIA y que desde su inmolación de HUATIO o de los milenarios Vichama Raymis de Paramonga para retribuir el amor a la Pachamama hacían un pozo en la tierra y con ayuda del poder de los dioses piedras calentaban con fuego y echaban el maíz, camotes y vegetales para resucitar la "luz" el espíritu de Vichama el hijo de la Pachamama, esta simple "HUATIA" se convierte en un plato mayor que es la PACHAMANCA, la olla que da de comer al universo, de cinco mil años de dioses.

Todas estas actividades, bajo la concepción: "pacha" que significa tierra y "manka" que significa olla, que literalmente vendría a ser olla de tierra”, Ychsmas (par luz - noche),

echar leña para producción de fuego, Pacha = universo y manca = olla, pozo en la huaca con leña y fuego en donde se deposita el maíz, camote y lúcumas o pepinos, génesis del pensamiento andino; OSCURIDAD $=$ NOCHE $=$ PACHACAMAC, SOL, LUZ, DIA = VICHAMA=ABUNDANCIA, HUECOS ABIERTO EN LA TIERRA = OLLA DE TIERRA = PACHAMANCA .

"Encontrado muchas muestras de pachamanca en todos los sitios existen áreas muy, muy, grandes en Caballete, por ejemplo existen puros restos de pachamanca" (Haas, 2013) 
"Sus orígenes datan de unos 7.000 a 8.000 años antes de cristo aproximadamente, ya que se ha encontrado en un abrigo rocoso llamado "Telarmachay", ubicado en San Pedro de cajas, cuyas evidencias de piedras caldeadas con las que el hombre andino cocía sus alimentos de carne de camélidos y otros animales silvestres, lo cual demostraría la antigüedad de esta milenaria costumbre". Donde "pacha" que significa tierra y "manka" que significa olla, que literalmente vendría a ser olla de tierra. En un pozo en la huaca con leña y fuego en donde se deposita el maíz, camote y lúcumas o pepinos. Así, también Ychsmas (par luz - noche) y echar leña para producción de fuego.

También Pacha $=$ universo y manca $=$ olla

Entonces se podría concluir que la génesis del pensamiento andino; OSCURIDAD $=$ NOCHE $=$ PACHACAMAC, SOL, LUZ, DIA=VICHAMA=AICA=ABUNDANCIA, HUECOS ABIERTO EN LA TIERRA $=$ OLLA DE TIERRA = PACHAMANCA, la abundancia como elementos contextuales ambientales del poder de la cosmogonía andina $=$ alto=hananc=guaca=templo=arquitectura monumental fue esta dialéctica racional ambiental que plasmó la conceptualización religiosa andina.

En tal sentido el origen del ritual religioso filosófico ambientalista expresado en los festinesrituales masivos del poder o los llamados Vichamas Raymis de Parmonguilla o Paramonga, tal como se puede apreciar en la Carta Annua de Luis Teruel al pasar por Huacho-Perú camino a la antigua Barranca y Cajatambo los abuelos originarios contaron las tradiciones de las moradas de las almas de Huacho a Barranca, registro en el contexto del Aya Marcay de Huacho a Paramonga que se celebra el 31 de Octubre, la primera morada referida a la Civilización Paramonga por la cual las almas pasaban el rio más caudaloso de la Barranca antigua, el rio Pativilca hacia el actual valle de fortaleza de Paramonga llamado AICA de abundancia agraria, alimentos y sanaciones:

[Primera Morada:] ...las almas de los que mueren van a lo aica, que es vn valle muy ameno en que. tienen// [fol. 3v. p. 52v.l tienen nuebas chacras. y siembran. y cojen como en esta vida, aunque con menos trabajo. Dizen ser el camino de Cenica ardiendo. en que se queman los pies los passajeros. y Despues ay un rio, que se passa por un puente de Cauellos muy caudaloso, pero es menester ser lleuados de perros negros o Vermejos, que crian para este effecto, $\mathbf{y}$ rnandan matar quando mueren. (Teruel, 1617).

Y la segunda y tercera morada referida a las Guacas o la arquitectura monumental milenaria se convirtió en la memoria histórica de las manifestaciones ideológicas de la religiones iniciaticas de la civilización andina, destacando en 1617 la tercera morada una de las "Guaca" en una isla Vaman cantac o Huaman Catax, la Guaca Oráculo del Cerro de la Horca de Paramonga hasta la llegada de los Inkas y las Guacas milenarias de Porvenir, Huaricanga y Caballete etc. de la Civilización Paramonga, que hasta hace unos 20años aún se acostumbraban los rituales chamánicos por los sanadores lugareños. [Segunda Morada: ] “... otros dizen tener por morada las almas en la otra vida la guaca que en esta adoraron”. 
(Teruel, 1617). [Tercera Morada:]..en particular vna que esta en vna isla que esta seis leguas la mar a dentro, llamada Vaman cantac, a donde son lleuados de vnos lobos marinos muy negros, de que en aquel paraje ay abundancia, y creen esto con tantas veras que tienen por graue pecado matar los tales lobos, que en su lengua llaman Turni. Ynuocan en sus necessidades a sus progenitores gentiles, y muchas vezes al aiio les ofrecen chicha, mais tostado, y otras cosas; y tenian particular hechizero, o Sacerdote, cuyo officio era llamar las almas de los difuntos. (Teruel, 1617).

Las actividades, religiosas masivas en las Guacas fueron abiertos integrados con la naturaleza para las grandes reuniones de peregrinajes para rituales a la pachamama, el agua, la luz-abundancia-agraria, pero las elites los ambientes fueron pequeños techados y muy reservados para reuniones de los personajes que entran en contactos con los dioses del fuego, agua, luz-agricultura el cual permite la producción y productividad de los alimentos. Estos desarrollos permitió un horizonte de razones para las edificaciones de las pirámides rectangular truncadas que se aprecian en demasías y perfectas en Caballete a orillas del rio Fortaleza y no advirtieron su mala ubicación al deslizamiento de los cerros arenosos y por el Fenómenos del Niño por la cual sucumbieron y motivaron su reubicación hacia el sur probablemente a la zona de Caral, donde se aprecia la solución Pluvial por su ubicación de conformación pétrea resistiendo por más de 1200años, traslado sin mayor problema, por su cercanía y factores favorables como la pesca y las salinas a pocos kilómetros al sur que favoreció a la técnica del pescado salado (charquikan) para llevar a zonas agrícolas donde hacían su vida diaria utilizando las Guacas, Huaca, Waka o Arquitectura Monumental para sus grandes vichama raymis, para sus ceremonias de intercambio de productos agrícolas.

Es así que algunos elementos arquitectónicos son usados para conservar la identidad de sus pensamientos andinos donde las edificaciones de diversas tradiciones arquitectónicas religiosas tuvieron que variar sus verdaderas funciones y darle otros mensajes. Alfredo José Altamirano Enciso y José María Arguedas Altamirano definen el termino Huaca o Waka enfatizando su variación de su verdadero entendimiento debido a la invasión hispana por acentuar el cristianismo y precisan "En el mundo andino, las múltiples formaciones sociales adaptadas a los diversos pisos ecológicos tenían una concepción altamente ritualizada del espacio y una fuerte religiosidad relacionada al culto a la Waka= lugar sagrado, seres anormales, ídolos, plantas sagradas y los cuatro elementos, al cual denominamos Wakanismo." ; De tal manera que para analizar este fenómeno cultural plantean en cinco categorías: “1) el culto al Achachila, Auqui, Jirca, Huamani o Wamani, entre otros (Huamanismo); 2) el culto a la huaca concerniente a las múltiples estructuras edificadas y seres sagrados; 3) el culto a las huancas y puquios[sangraderas en la costa son filtraciones de agua producto de la frágil capa freatica]; 4) el culto a los muertos y 5) el culto a los ídolos o fetiches. Es así que algunos elementos arquitectónicos junto a los 
vichama raymis es la memoria histórica y son usados para conservar la identidad de sus pensamientos filosóficos-comunicológicos ambientales de la abundancia agraria, alimentaria y el desarrollo de las sanaciones de la civilización andina.

\section{METODOLOGIA}

La fase inicial de este proyecto se apoya en tres decisiones que acotan el objeto y condicionan el método de investigación. En primer lugar, pareció conveniente comenzar por el análisis de la investigación publicada en las revistas científicas especializadas en la temática. Y las revistas ocupan una posición en el sistema de difusión de los resultados científicos que justifica la opción tomada.

Por otra parte, y respondiendo a su consideración de publicaciones científicas, las revistas arbitran unos procedimientos de selección y filtro de originales que garantizan a priori un nivel de calidad adecuado en los trabajos que difunden. De igual manera este mismo artículo ya publicado en el mismo contexto indicado. Dicho de otro modo, los textos incluidos en este tipo de publicaciones debieran representar la buena investigación, aquella atenida exclusivamente a los criterios de rigor y validez científicos. Decidimos centrar el análisis y el desarrollo, el conocimiento de lo que se está haciendo en los últimos años, en materia de investigación arqueológica en el Norte Chico del Perú, como apuntamos ante el cruce de información con datos antropológicos, ritos contemporáneos y fuentes de la cultura viva.

\section{DISCUSIÓN}

Que, el descubrimiento definitivo sobre el cultivo y consumo masivo de maíz, camote y cientos de plantas domesticadas en el Arcaico Tardío de Cinco Mil años en Caballete y Huaricanga del Valle Fortaleza de Paramonga define que la sociedad de los inicios de la civilización andina fue agraria, no pesquera ni el comercio su desarrollo de estas últimas fue una fase posterior del desarrollo civilizatorio.

Que, la existencia de miles de evidencias físicas de restos pachamancas en campamentos temporales definen su consumo masivo como la dieta en el Arcaico Tardío de Cinco Mil años en Caballete y Huaricanga del Valle Fortaleza de Paramonga a través de 1 uso del tacú tacú o mistura, ritual masivo de la pachamanca, esa mezcla o misturas de alimentos fue producto de la llegada de miles de insumos alimentarios de la costa, sierra y selva traídos por los peregrinos religiosos temporales al Valle Fortaleza y al Norte Chico.

Que, los rituales estuvieron diferenciadas por la elite del poder a través de ritual de la quema de alimentos sagrados para la interpretación semiótica de la ubicación de los alimentos y del humo; maíz, camote, yuca (solo uso ceremonial) guayaba, etc. en recintos pequeños muy privados que servían como 
aulas de universidades del conocimiento, sabiduría y probable uso de sanaciones de la elite mientras en los anfiteatros hundidos y las Guacas para uso masivo de la población.

Que, la forma del poder del Ritual ambientalista para el manejo social se expresó en FESTINES conocidos como los Vichamas Raymis de Paramonga en donde el manejo psicosocial del discurso de los sacerdotes o chamanes utilizó el tacú tacú o mistura de la pachamanca para estimular el intercambio de estos por la fuerza de trabajo cooperativo para el desarrollo y crecimiento de los inicios de la civilización andina, patrimonio del Valle Fortaleza y de la Provincia de Barranca.

Que, las Guacas o Huacas sagradas (parroquias, iglesias y grandes templos y catedrales-pirámides truncadas) es la arquitectura monumental del arcaico tardío de la Civilización Paramonga y del Norte Chico del Perú fue producto del alto desarrollo de la ciencias ambientales y comunicológicas en los estudios de los paisajes culturales y del cosmos las tecnología, técnicas y el arte expresados en conocimientos y sabidurías milenarias andinas al parecer la idea de la teoría de la arquitectura no solo nació en las Escuelas de Bellas Artes francesas, ya en los inicios de la civilización andina en Porvenir, Caballete. Huaricanga, etc. posteriormente en Caral las pirámides truncadas fueron concebidas fundamentalmente por la función de su parte superior como observatorios del cosmos para poder pronosticar los periodos de las siembras, etc. tomando conciencia ambiental sobre la naturaleza finita de los recursos energéticos y naturales más empleados y la necesidad de preservarlos.

Conclusiones: La forma del poder del Ritual ambientalista para el manejo social se expresó en las fiesta-festines de rituales del poder ambiental conocidos como los Vichama Raymis, las fiestas del origen de la agricultura ,abundancia de los alimentos y sanaciones de la Civilización Milenaria de Paramonga en donde el manejo de guerras psicosociales positivos a través del discurso comunicológico de los sacerdotes o chamanes utilizó el tacú tacú o mistura de la pachamanca la dieta masiva-religiosa para estimular el intercambio la fuerza de trabajo colaborativo y no la pesca ni el comercio permitió el desarrollo de la civilización andina para el desarrollo de las grandes edificaciones de las Guacas o arquitectura monumental en donde las pirámides truncadas se definen como observatorios del cosmos en el desarrollo y crecimiento agrario, patrimonio del Valle Fortaleza y de la Provincia de Barranca, Mañaca o crisol de la civilización andina. 


\title{
FUENTES DE INFORMACIÓN BIBLIOGRAFICA
}

Fuentes documentales

Arriaga, P.,Pablo Joseph de la Extirpación de Idolatrías en el Perú, 1661, CLDRHP, t.r. 2a serie Lima, 1920. R.

Centeno Sara-Lafosse, R. V. (2004). Arquitectura pública del arcaico tardío en el valle de Fortaleza. reflexiones sobre las sociedades complejas tempranas en la costa nor-central. Revistas de investigación, 221. Obtenido de http://revistas.pucp.edu.pe/index.php/boletindearqueologia/article/view/1384/1337

Chu Barrera, Alejandro, (2008) Arena, mar y humedal en el surgimiento de la Civilización Andina. Primera Edición, junio de 2008 Huacho. Obtenido de

http://aplicaciones.cientifica.edu.pe/repositorio/catalogo/_data/14.pdf

Dictamen Recaido en el Proyecto de Ley 1730/2012-CR en la cual de proponen la ley que incorpora la escenificación de la ceremonia ritual "vichama raymi" en el articulo 02 de la Ley que oficializa los festivales rituales de identidad nacional. Obtenido de https://www2.congreso.gob.pe/Sicr/ApoyComisiones/comision2011.nsf/DictamenesFuturo/574C68001 941CDF305257B9C005B5DD0/\$FILE/COM.EXT.T._1730-2012-CR_TxT.Fav.Sust.Unan..pdf

\author{
Jonathan Haas, Winifred Creamer, Luis Huamán Mesía, David Goldstein, Karl \\ Reinhard y Cindy Vergel Rodríguez (2013) Evidencia de maíz ( Zea mays ) en el Arcaico Tardío (3000- \\ 1800 aC) en la región Norte Chico de Perú. Revista de la Academia Nacional de Ciencias (NAS) PNAS. \\ Obtenido de \\ https://www.pnas.org/content/110/13/4945
}

Marcelo Castillo, Henry (2020) Dioses kon de parmonguilla y estrategias psicosociales positivas para la producción agraria y sanación de pandemias en la civilización andina, Huacho, Perú (pp. 01-25)

Marcelo Castillo, Henry; Jorge Persi Ramírez Príncipe, Melvin D. Marcelo C (2020) El ritual Vichama Raymi de Parmonguilla: Configuraciones de un mito y el resguardo de una conciencia ambiental (pp.0199). Disponible https://www.ilae.edu.co/web/libros-html/libro-641/index.html

Piscitelli, M. 2013 A Brand New Toolbox: Using Modern Science to Reconstruct Ancient Ritual in Peru. Paper presented at the 41st Annual Midwest Conference of Andean and Amazonian Archaeology and Ethnohistory. Dekalb, IL. 2014 Ritual is Power? Late Archaic Small-Scale Ceremonial Architecture in the Central Andes. Ph.D. dissertation, Department of Anthropology, University of Illinois at Chicago.

Polia. (1611-1613). Siete cartas inéditas del Archivo Romano de la Compafiia de Jesds(161 1-1613) huacas, mitos y ritos andinos. Disponible

http://revistas.pucp.edu.pe/index.php/anthropologica/article/viewFile/2030/1964

Ruiz, A. and J. Haas 2007 Proyecto de Investigación Arqueológica: Excavaciones en Huaricanga, Valle de Fortaleza, Perú. Informe Final submitted to the Instituto Nacional de Cultura, Lima, Perú.

Shady Solis Ruth, (2006) ¿La primera ci de Estados Unidos? El caso del caral arcaico tardío. Editorial: Springer US. Lima Perú. Obtenido de https://www.scopus.com/record/display.uri?eid=2-s2.084879964969\&origin=inward\&txGid=5ef692bd7197cfc78d02b2eca76a997e 
Winifred Creamer, Jonathan Haas, and Henry Marcelo Castillo, (2017) A culturescape built over 5,000 years, archaeology, and Vichama Raymi in the forge of history, $(189,208)$ University Press of Colorado, E.U. 